\title{
Endoscopic management of gastric outlet obstruction disease
}

\author{
Alberto Tringalia ${ }^{\text {, Aurora Giannettia,b, Douglas G. Adler }}{ }^{\mathrm{c}}$
}

ASST GOM Niguarda, Milan, Italy; University of Palermo, Italy; University of Utah School of Medicine, Salt Lake City, Utah, USA

\begin{abstract}
Gastric outlet obstruction (GOO) is a clinical syndrome characterized by a variety of symptoms. It may be caused by motor disorders and by benign or malignant mechanical disease. Endoscopic management of benign disease is mainly based on balloon dilation, augmented by the use of covered self-expanding metal stents (SEMS) in refractory disease. Endoscopic ultrasound-guided gastroenterostomy (EUS-GE) is increasingly used as an alternative method, although more studies with longer follow up are needed before it can be considered as a recommended therapy. Surgery remains the last resort. Endoscopic management of malignant GOO is based on SEMS placement as an alternative to palliative surgery, because it is a cost-effective method. The use of a covered or uncovered stent depends on patient-related variables, which include the stricture site, concomitant involvement of the bile duct, the patient's prognosis, probably the tumor type, and the use of chemotherapy. EUS-GE is a promising technique but needs more studies with longer follow up before any firm conclusions can be drawn.
\end{abstract}

Keywords Gastric outlet obstruction disease, endoscopic balloon dilation, metal stents, endoscopic ultrasound-guided gastroenterostomy

Ann Gastroenterol 2019; 32 (4): 1-8

\section{Introduction}

Gastric outlet obstruction (GOO) is a clinical syndrome characterized by epigastric abdominal pain and postprandial vomiting, eventually associated with nausea, abdominal bloating or discomfort, early satiety, and weight loss. The causes can be divided into mechanical causes and motility disorders. This article will discuss only the endoscopic treatments of GOO due to mechanical obstructions.

GOO typically involves the distal stomach and/or the proximal small intestine, but can affect the small bowel distal to this point. The most common cause of motility disorders is gastroparesis, which can result from long-term diabetes, viral

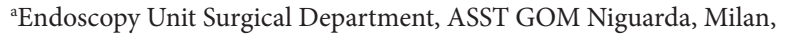
Italy (Alberto Tringali, Aurora Giannetti); bSection of Gastroenterology, Biomedical Department of Internal and Specialized Medicine (DI. BI.M.I.S.), University of Palermo, Palermo, Italy (Aurora Giannetti); ${ }^{\mathrm{c}}$ Gastroenterology, and Hepatology Department, University of Utah School of Medicine, Salt Lake City, Utah USA (Douglas G. Adler)

\section{Conflict of Interest: None}

Correspondence to: Alberto Tringali MD, Endoscopy Unit, Surgical Department, ASST GOM Niguarda, Piazza Ospedale Maggiore 3, 20162 Milan, Italy, e-mail: alberto.tringali@ospedaleniguarda.it, albtri10@gmail.com

Received 18 January 2019; accepted 7 April 2019; published online 30 May 2019

DOI: https://doi.org/10.20524/aog.2019.0390 damage or from an unknown drug or origin (idiopathic). The incidence of GOO is not known with precision. It is likely to have decreased in recent years because of the decline of peptic ulcer disease-which historically has been a major cause of GOO-as a result of the identification of Helicobacter pylori (H. pylori) and the use of proton pump inhibitors. In contrast, in recent decades, $50-80 \%$ of cases were attributable to cancer [1-4].

\section{Benign mechanical obstruction}

Among the benign causes, the most frequent is peptic ulcer disease, which accounts for approx. 90\% of cases. Other less frequent causes include caustic ingestion, Crohn's disease, strictures related to nonsteroidal anti-inflammatory drugs, anastomotic or post-radiation strictures, benign polyps, gastric tuberculosis or gastric bezoars, gastric volvulus, eosinophilic gastroenteritis, Bouveret syndrome, annular pancreas, post-surgical stricture, extrinsic compression from chronic pancreatitis or severe acute pancreatitis, especially in the case of walled-off pancreatic necrosis or large pseudocyst.

Conservative measures should be attempted first in patients with GOO related to peptic ulcer disease: these include acid suppression, avoidance of nonsteroidal anti-inflammatory drugs, and, when applicable, H. pylori eradication [5]. Patients who fail to respond to medical therapy may require endoscopic dilation or surgery [6]. 


\section{Endoscopic balloon dilation (EBD): technique and procedure description}

Endoscopy is performed to visualize the narrowed gastric or duodenal segment and look for the presence of active ulcer. Computed tomography scanning to evaluate the thickness of the antral wall can be a good way to exclude neoplasia. If the stricture segment can be identified and a balloon can be passed, dilation is an appropriate option in experienced hands. A water-soluble contrast study may be helpful to define the anatomy before dilation.

Dilation can be accomplished using endoscopy and a balloon dilator inserted through the working channel of the scope, or by using a balloon placed over a guidewire positioned under fluoroscopic guidance (Fig. 1). The currently used pyloric balloon dilators are available from a number of manufacturers, with lengths of 5.5-8.0 cm and diameters of 6-20 mm, and are inflated using a hydrostatic device attached to a pressure gauge. The dilation time has not been standardized, but the balloon is usually kept inflated for one minute. The amount of dilation in a single session is determined by the initial diameter of the stricture. Narrow strictures may require stepwise dilation performed over multiple sessions. The frequency with which dilations are repeated depends on the technical success of the initial dilation and the clinical response. Such patients may require repeated sessions every 5-7 days. After sufficient progress is made, less frequent dilating sessions may be satisfactory. In some patients, however, the symptoms tend to recur rapidly after dilation and others require more frequent dilations.

EBD is often successful in the short term with immediate symptom improvement, usually with successful dilation to $12 \mathrm{~mm}$. There may be an advantage to postponing dilation beyond $15 \mathrm{~mm}$ until after a period of medical management. Once adequate dilation is achieved, a lasting clinical response is observed in $70-80 \%$ of patients [7,8]. Long-term results often require more dilation. Recurrence of stenosis after EBD
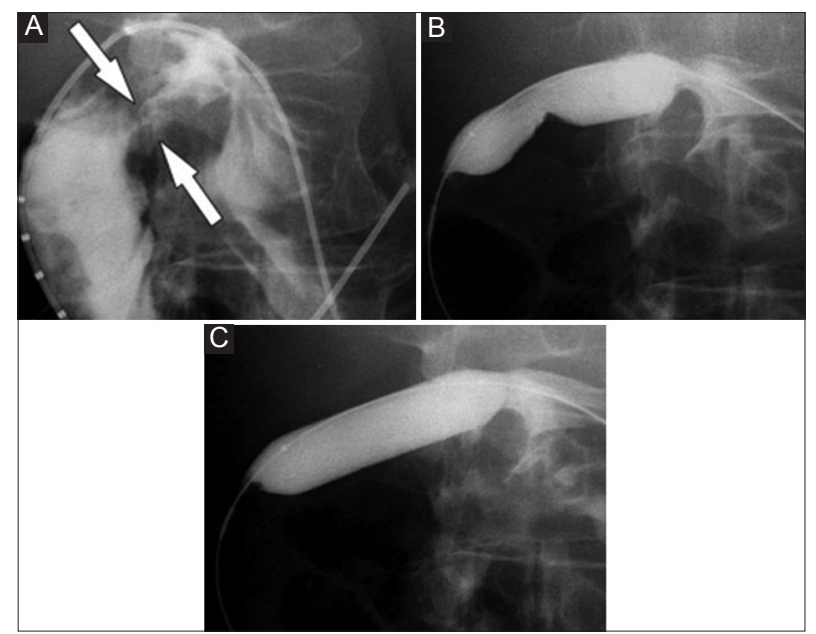

Figure 1 Duodenal balloon dilation over the wire. The sequence of images shows (A) the identification of the anatomy of the stricture with water-soluble contrast medium, (B) the balloon placed over a guidewire positioned under fluoroscopic guidance, and (C) its dilation until the desired diameter is reached is likely to be an indication for surgery. A study has shown that the need for 2 or more dilations is associated with a higher probability of surgery [9].

Hydrostatic balloon dilation is generally a safe procedure, with perforation rates in benign peptic stenoses ranging from $3-6 \%$, the higher rates corresponding to a balloon diameter greater than $15 \mathrm{~mm}$ [10-12]. As complications, minor bleeding and pain during EBD are not uncommon, usually self-limiting, whereas arterial bleeding has rarely been reported [13].

\section{Balloon dilation for caustic GOO}

Balloon dilation may also be effective in treating causticinduced GOO or stenosis after endoscopic submucosal pylorus dissection [14,15]. Specifically, about one third of patients who ingest strong caustic substances end up having GOO. In a study of 41 cases of acid ingestion, it was reported that $44.4 \%$ developed GOO [16], while in another study on the ingestion of alkalis, $36.8 \%$ of 31 patients developed GOO [17]. A recently published single-center experience shows a $97.3 \%$ clinical success rate for EBD, without relapses over a 98-month follow-up period. Complications (perforation) occurred in 2 patients [18].

Surgery has been the cornestone of the treatment for caustic-induced GOO, but recent studies suggest that EBD may be an effective alternative form of therapy in a selected subgroup of patients $[15,19]$. However, compared to GO due to peptic disease, these patients require a greater number of EBD sessions and have a higher rate of stenosis recurrence [20].

\section{Role of fully coated self-expanding metal stents (SEMS)}

Experience of placing SEMS for the treatment of GOO due to peptic ulcer is very limited, although clinical cases have been reported with the use of these devices in this type of population [21-23]. One case series describes temporary placement of SEMS [22] in patients with pyloric stenosis who failed to respond to balloon dilation or refused surgery. Two of 4 patients were treated with pyloric stents, each for a duration of 12 weeks and 8 days. There was no recurrence of stenosis in a follow up between 34 and 39 months. SEMS removal is usually performed 6-8 weeks after insertion.

\section{Role of lumen-apposing metal stents (LAMS)}

A growing pool of data has demonstrated that LAMS provide a new option for the effective endoscopic management of benign GOO. A recent retrospective study, including 19 patients with benign GOO, showed a clinical success of $67 \%$, with a migration rate of $12 \%$ and an adverse event rate of $12 \%[24,25]$. A pooled analysis that included 4 studies with a total of 65 patients, analyzing the role of LAMS in the treatment of GOO, showed that technical success was $98.4 \%$ and short-term clinical success was $78.4 \%$, while long-term clinical success was $67.5 \%$ and migration rate was $8.5 \%$ [24-27]. 
Further investigation, via a multicenter prospective casecontrol study or a randomized controlled trial comparing LAMS to repeat dilation or other SEMS, is needed to assess the most clinically effective and cost-effective approach to benign GOO. Definitive treatment of the obstruction should be based upon the underlying etiology and may including stenting, chemotherapy, EBD, or surgery.

\section{Surgery}

If surgery is considered, presurgical optimization of the patient's nutritional status may be necessary. Surgery is indicated if the pylorus is obstructed and cannot be safely dilated, or if the obstruction persists or recurs despite medical and endoscopic management. An algorithm of treatment for benign mechanical obstruction is presented in Fig. 2.

\section{Malignant obstruction}

Malignant mechanical GOO usually results from cancer affecting the antropyloric zone, pylorobulbar area, and descending duodenum or postbulbar area. The most common cause is distal gastric cancer, which accounts for up to $35 \%$ of

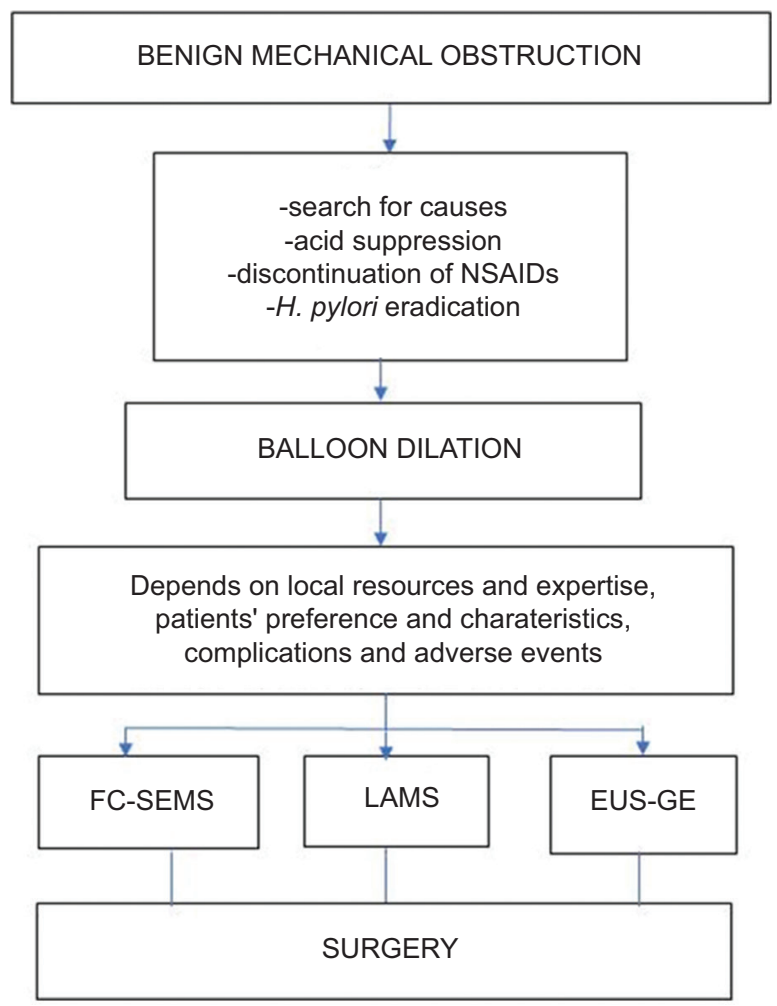

Figure 2 Algorithm for treatment of benign gastric outlet obstruction disease

NSAID, non steroidal anti-inflammatory drugs; $H$. pylori, Helicobacter pylori; FC-SEMS, fully coated self-expanding metal stent; LAMS, lumenapposing stent; EUS-GE, endoscopic ultrasound-guided gastroenterostomy
GOO cases [28], and pancreatic adenocarcinoma with extension to the duodenum or stomach [29]. Other infrequent causes of malignant GOO include gastric lymphoma, large neoplasms of the proximal duodenum and ampulla, local extension of advanced gallbladder carcinoma or cholangiocarcinoma, metastatic or primary malignancy in the duodenum, and gastric carcinoid. Fifteen to $25 \%$ of patients with pancreatic cancer present with GOO and such patients also commonly have biliary obstruction [29-34]. Some reports highlighted the possibility of biliary metastasis from gastric cancer-causing jaundice [35-38].

Mutignani et al [39] have suggested a classification of "bilioduodenal" stenosis into 3 types, taking into account the anatomical location of the duodenal stenosis in relation to the papilla and its involvement: stenosis type I occurs at the level of the duodenal bulb or upper duodenal genu, but without the involvement of the papilla; type II stenosis affects the second duodenal portion, involving the papilla; and stenosis type III involves the third part of the duodenum, distally and without the involvement of the papilla. This classification suggests endoscopic management in cases of type II malignant stenosis, with a combined endoscopic biliary and duodenal SEMS as a safe and effective procedure for palliation in malignant biliary and duodenal strictures.

Treatment options include resection or bypass surgery, and endoscopy through endoscopic stenting, decompressive gastrostomy with or without feeding tube placement and endoscopic ultrasound (EUS)-guided gastroenterostomy (GE). Surgery is the treatment of choice when resection can be potentially curative. Diagnostic laparoscopy or exploratory laparotomy can be used to assess the extent of the disease with the intention of performing a surgical bypass as a palliative treatment. An endoscopic stent should be used if there is no evidence of obstruction distal to the site where it should be placed. In patients with multiple sites of obstruction, a decompressive gastrostomy with jejunal feeding or total parenteral nutrition may be considered.

\section{Enteral SEMS}

Mechanical malignant GOO can be treated with duodenal SEMS as a palliative measure (Fig. 3). The goals of stent placement are to provide relief from obstructive symptoms, to allow the patient to resume oral nutrition, hydration and drug delivery, and to improve the patient's quality of life. The placement of a stent in the presence of free perforation or severe cardiopulmonary disease is contraindicated. Symptom relief is assessed by the GOO score, which evaluates the severity of symptoms defined as satiety, nausea and early vomiting, assigning a score based on the patient's oral intake level [30] (Table 1).

The technical and clinical success rates are 97\% (range 91$100 \%$ ) and $89 \%$ (range $63-95 \%$ ), respectively, according to a systematic review by Dorman et al [40]. This discrepancy is due to many factors, such as underlying gastrointestinal dysmotility, neural tumor involvement, distal obstruction secondary to peritoneal carcinomatosis, and general conditions and anorexia caused by the tumor $[41,42]$. 
Patients considered for SEMS placement should have a short life expectancy of less than 2-6 months [43], according to estimates by the World Health Organization. Patients with a performance status of 3 or 4 had a 3 -month survival rate of $26 \%$, compared to $60 \%$ for patients with a performance status of $0-2$ [44].

Coexistent biliary obstruction is commonly present because it typically develops before gastric outlet obstruction (e.g., in patients with pancreatic cancer) [30,38]. If there is a known or imminent biliary obstruction, a metal biliary SEMS should be placed before the duodenal one, because it can be difficult to access the biliary tract once a duodenal stent has been placed through the papilla (Fig. 4) [45].

\section{Materials, insertion technique and procedure description}

SEMS consist of woven, knitted or laser-cut metal mesh that exerts self-expanding forces until they reach their maximum fixed diameter. They are cylindrical in shape and are loaded inside a delivery device in a compressed form. SEMS are composed of stainless steel, alloys such as elgiloy and nitinol, or a combination of nitinol and silicone. Nitinol, a nickel and titanium alloy, provides greater flexibility, useful for stenting sharply angulated regions at the cost of a lower radial force in comparison with stents made with other metals, but also retains a shape-memory of the original configuration.

All SEMs are available in various lengths and diameters. Most have a proximal and/or distal flare to prevent migration. The choice of stent should take into consideration that they shorten during deployment and that their length should ideally exceed the stricture length by at least $2 \mathrm{~cm}$.

\section{Post-procedure care}

Complete stent expansion generally occurs within 24-48 h, although with very narrow strictures expansion may take longer, or the stent may not expand completely. Patients are allowed to start a liquid diet following the procedure and to carefully advance their diet towards a low-residue diet.

\section{Covered vs. uncovered SEMS}

Uncovered stents are generally used for the treatment of malignant GOO because they are less prone to migration and are more flexible, but the tumor can grow into the stent and obstruct it over time. In addition, uncovered stents allow for bile flow through the stent interstices in patients with previously placed biliary stents.

Table 1 The gastric outlet obstruction scoring system

\begin{tabular}{lc}
\hline Level of oral intake & Score \\
\hline No oral intake & 0 \\
Liquids only & 1 \\
Soft solids & 2 \\
Low residue or full diet & 3 \\
\hline
\end{tabular}

Covered stents are increasingly used in Europe, because they offer the advantage of less tumor ingrowth; however, they are more prone to migration than uncovered stents and are less flexible [46,47]. In addition, covered stents have some risk of biliary outflow blockage when the papilla of Vater is covered by the SEMS.

Stent migration within 8 weeks of placement was significantly more common with covered SEMS compared with uncovered SEMS (28\% vs. 3\%) [48]. When a stent migrates distally, repositioning or removal can be attempted, or, if repositioning fails, the placement of an additional SEMS is usually effective $[49,50]$. Completely migrated stents can cause intestinal obstruction that requires surgical intervention [49,51].

Stents can be placed successfully in over $90 \%$ of patients, with clinical success rates typically of $80 \%$ or higher [49,52-56]. Technical failure is usually due to the inability to pass a guidewire through the stricture or to anatomical abnormalities either post-surgery or secondary to the stenosis, such as an excessive loop in a dilated stomach [30].

A comparison of efficacy and safety between uncovered and covered SEMS used for palliation of malignant GOO was made in 3 meta-analyses. No significant differences between covered and uncovered SEMS were observed in technical and clinical success, long-term stent patency or overall complications. A trend

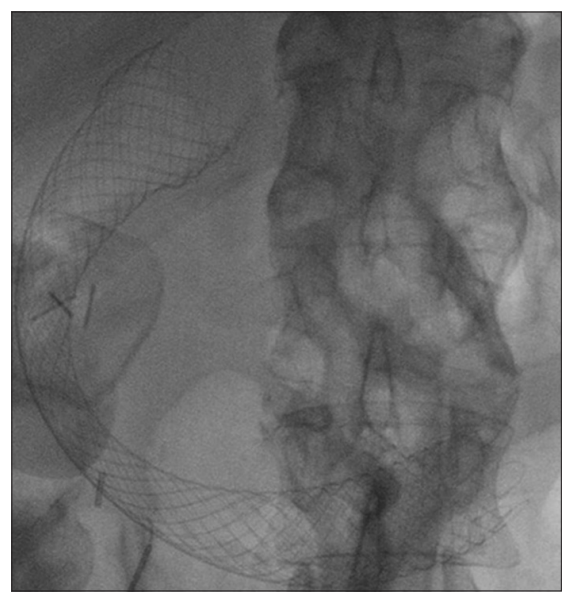

Figure 3 Enteral self-expanding metal stent

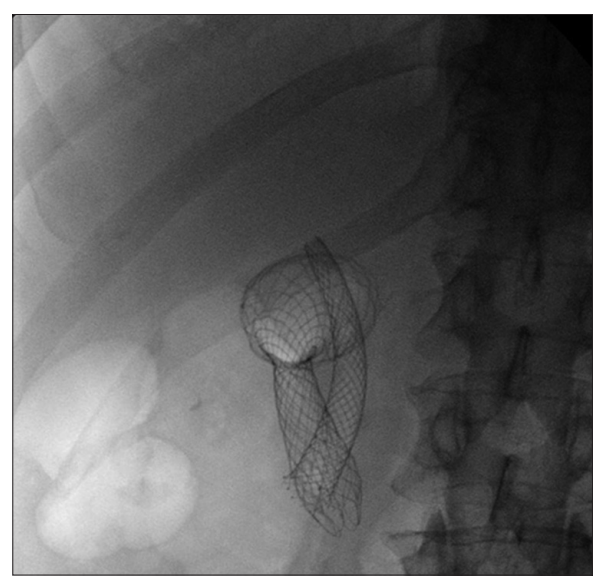

Figure 4 Bilio-duodenal self-expanding metal stent 
toward a higher rate of overall adverse events in covered SEMS was observed, but only if they included minimal bleeding [57]. Partially covered stents (with uncovered proximal and distal ends to decrease migration and with a covered middle portion to decrease tumor ingrowth) are under development. The use of a covered or uncovered stent depends on patient-related variables, which include the location of the stenosis, concomitant involvement of the bile duct, the patient's clinical and nutritional status, and the prognosis. Taking into consideration that the most common causes of stent dysfunction in covered and uncovered SEMS were migration and occlusion, respectively [58-60], the choice of the best stent to use should be tailored to each individual patient.

Tumor ingrowth/overgrowth has been reported in $17.2 \%$ of patients who received bare-metal stents and in $6.9 \%$ of those with covered stents [62-63]. The management of stent dysfunction is mainly based on the stent-in-stent technique [64] (Fig. 5), which has had excellent technical and clinical success rates. The occlusion rates after secondary SEMS placement range from $10-34 \%[65,66]$.

\section{SEMS vs. surgery}

Many comparative studies have discussed the optimal modality for palliation of malignant GOO, comparing endoscopic and surgical methods. In a systematic review, patients treated with enteral stents were more likely to tolerate and resume oral intake more quickly (mean difference 7 days) and had shorter hospital stays (mean difference 12 days) than patients treated with gastrojejunostomy, though there were no significant differences in mortality and overall complications or in survival [67]. A retrospective study of 95 patients undergoing duodenal stenting or gastrojejunostomy suggested that stent placement is associated with better short-term results and gastroduodenostomy with better long-term results. In particular, those who underwent SEMS placement showed faster development of late complications ( $>7$ days), including recurrent obstructive symptoms and the need for reoperation during 3 months of follow up, but a shorter hospital stay [68].

Three prospective randomized studies comparing SEMS and surgery have been reported $[43,69,70]$. One study showed an improvement in the quality-of-life score in patients with SEMS but none with surgical bypass [64,69], while another did not show a difference between the groups [43]. All 3 studies showed comparable results in terms of technical success and mortality, with longer hospital stays in the operative group.

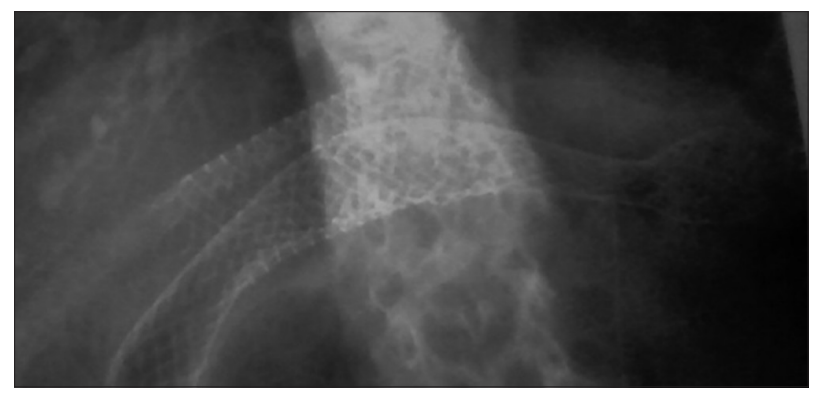

Figure 5 Stent in stent
SEMS placement was associated with a more rapid improvement in symptoms $[43,58,70]$. In a larger randomized trial with a longer follow up, late complications (e.g., recurrent obstruction and need for reoperation) were more common with SEMS than with gastrojejunostomy, confirming the results of a previous retrospective study that suggested a benefit for gastrojejunostomy surgery in patients with a longer life expectancy $[53,68,71]$.

Several studies have compared the cost of endoscopic stenting with those of palliative gastrojejunostomy and all agree that the endoscopic approach is more convenient [60,72-74]. An analytical decision model comparing open gastrojejunostomy, laparoscopic gastrojejunostomy and endoscopic stenting for malignant gastroduodenal obstruction showed that the placement of SEMS was the most convenient strategy and was associated with the lowest complication rate and the highest rate of success within 1 month [75].

\section{Percutaneous decompressive gastrostomy (PDG)}

When malignant GOO is not amenable to surgical bypass or endoscopic SEMS placement for peritoneal carcinomatosis with or without diffuse bowel stricture, it is possible to use PDG with a high rate of symptom relief (90\%) [76]. PDG with jejunal extension allows decompression with access for enteral nutrition. Ascites could be a relative contraindication to PDG; however, paracentesis before PDG may facilitate the successful placement.

\section{EUS-GE}

EUS-guided gastrojejunostomy using LAMS has also been evaluated, since it can allow sustained palliation of surgical bypass while maintaining a minimally invasive endoscopic approach $[77,78]$. With this technique, a bypass is created by inserting a stent from the stomach to the small bowel distal to the obstruction under EUS and fluoroscopic guidance. At the present time, 3 types of techniques have been described for performing EUS-GE using bi-flanged LAMS. All 3 methods require a therapeutic linear echoendoscope and a LAMS to ultimately create the gastrojejunostomy, but they differ from each other with regard to the method of locating the jejunal loop before the EUS-guided transgastric puncture.

1. Direct EUS-GE technique. This approach is feasible even in cases where complete lumen obstruction prevents traversal of the site with a scope or a guidewire. The target small bowel loop is identified and confirmed by contrast injection with the help of EUS-guided needle puncture (19 or $22 \mathrm{G}$ ).

2. Balloon-assisted EUS-GE using a retrieval/dilating balloon, single balloon overtube, nasobiliary drain, and ultraslim endoscope. In this approach, the area of stenosis is traversed either by the endoscope itself or by a guidewire under fluoroscopic guidance. A balloon dilator or nasobiliary drain is then passed over the guidewire and the balloon is filled with contrast to locate the jejunal loop. The inflated balloon is then located endosonographically and a transgastric puncture is performed with the goal of bursting the balloon (Fig. 6). 
3. EUS-guided double balloon-occluded gastrojejunostomy bypass $[79,80]$. A proprietary double-balloon enteric tube (Create Medic Co., Ltd., Yokohama, Japan) is passed over a 0.089-inch guidewire or through an overtube into the jejunum beyond the ligament of Treitz. The 2 balloons are inflated and the lumen between them is filled and distended with saline/contrast in order to easily allow the transgastric endosonographic location. The subsequent puncture and stent deployment are performed using the one- or two-step method described previously.

EUS-GE can be used for malignant and also benign outlet obstruction. Two recent case series demonstrated high technical (90-92\%) and clinical (85-92\%) success rates, with a variable percentage of adverse events $(0-11.5 \%)[81,82]$. EUSGE is associated with fewer adverse events (12\% vs. $41 \%)$ and with similar technical success ( $88 \%$ vs. $100 \%)$ compared to surgical laparoscopic gastrojejunostomy [81]. Khashab et al reported a higher technical success rate in the open surgical

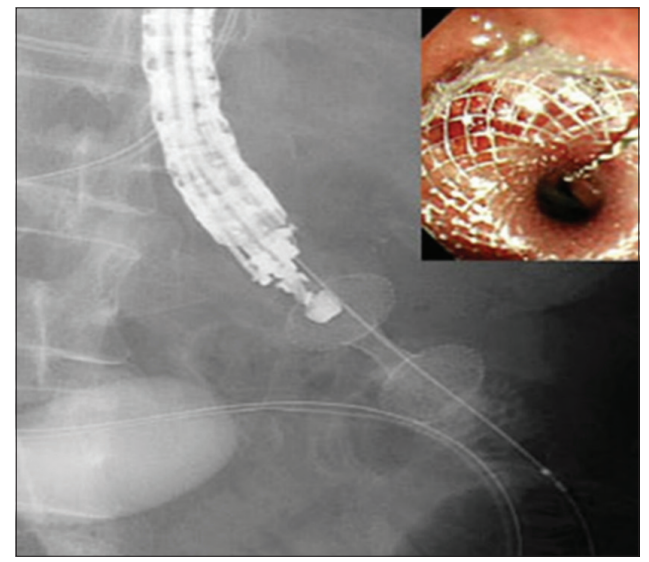

Figure 6 Endoscopic ultrasound-guided balloon-assisted gastroenterostomy. Radiological and endoscopic image of the positioning of a lumen-apposing metal stent after a contrast-filled balloon was used to identify the jejunal loop

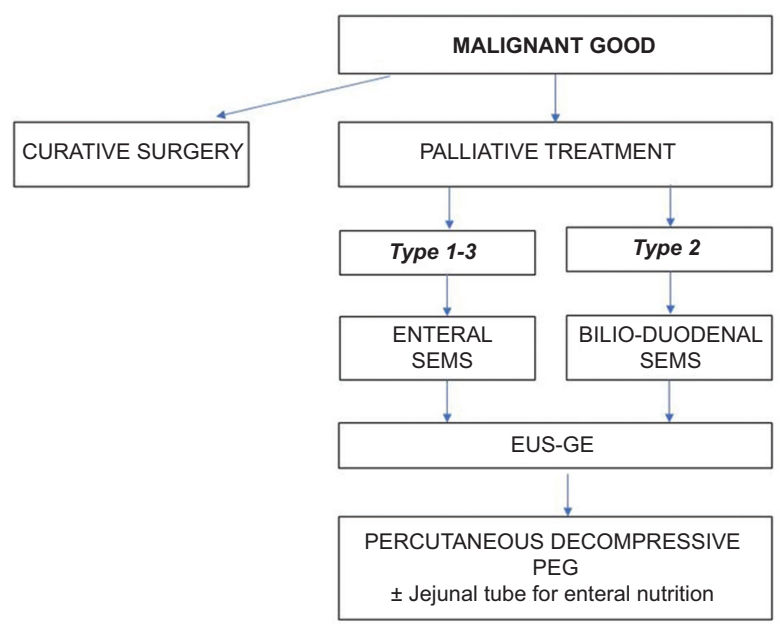

Figure 7 Algorithm for treatment of malignant gastric outlet obstruction disease

SEMS, self-expanding metal stent; EUS-GE, endoscopic ultrasoundguided gastroenterostomy; PEG, percutaneous endoscopic gastrostomy gastrojejunostomy group ( $100 \%$ vs. $87 \%)$, but similar clinical success rates ( $90 \%$ vs. $87 \%$ ) [80].

The first comparative trial to compare EUS-GE and enteral stents found similar rates of technical and clinical success, length of stay post-procedure, and rates and severity of adverse events, while EUS-GE showed fewer recurrences of GOO and need for reintervention. The main limitation of this study was that it involved only tertiary centers, making it difficult to extend its results to smaller and community practices. EUSGE is still considered experimental. The main strength of this study is that it provided a large EUS-GE cohort in the literature.

In conclusion, available studies have revealed the feasibility of a novel EUS-GE technique using a LAMS. As a next step, clinical prospective trials with adequate sample size-and moreover, with a comparison between EUS-GE and duodenal metal stenting or surgical GE-are warranted. However, until these outcomes are clarified, this endoscopic technique should be undertaken only by experienced endosonographers in a multidisciplinary approach with surgeons and interventional radiologists. An algorithm for the management of malignant GOOS is provided in Fig. 7.

\section{Concluding remarks}

Endoscopic dilatation is the gold standard of treatment for benign strictures; the role of fully coated SEMS needs further evaluation. SEMS placement is recommended for the treatment of a malignant gastroduodenal obstruction in patients with a poor performance status and/or short life expectancy, according to efficacy, safety and costs. For other patients with malignant gastroduodenal obstruction, surgical gastrojejunostomy may offer a more durable result. The use of a covered or uncovered stent depends on patient-related variables, including the location of the stenosis, concomitant involvement of the bile duct, the patient's prognosis, and probably the tumor type and use of chemotherapy. The palliative approach chosen should depend on local expertise and the patient's prognosis and preferences. EUS-GE is a promising technique, but needs a longer follow up and should be performed only in third-level centers by expert endoscopists.

\section{References}

1. Johnson CD. Gastric outlet obstruction malignant until proved otherwise. Am J Gastroenterol 1995;90:1740.

2. Shone DN, Nikoomanesh P, Smith-Meek MM, Bender JS. Malignancy is the most common cause of gastric outlet obstruction in the era of H2 blockers. Am J Gastroenterol 1995;90:1769-1770.

3. Johnson CD, Ellis H. Gastric outlet obstruction now predicts malignancy. Br J Surg 1990;77:1023-1024.

4. Chowdhury A, Dhali GK, Banerjee PK. Etiology of gastric outlet obstruction. Am J Gastroenterol 1996;91:1679.

5. Cherian PT, Cherian S, Singh P. Long-term follow-up of patients with gastric outlet obstruction related to peptic ulcer disease treated with endoscopic balloon dilatation and drug therapy. Gastrointest Endosc 2007;66:491-497.

6. Graham D. Ulcer complications and their non-operative treatment. In: Sleisenger MH, Fordtran JS (editors). Gastrointestinal disease: 
pathophysiology, diagnosis, management, $5^{\text {th }}$ ed. WB Saunders: Philadelphia; 1993, pp. 698-712.

7. Solt J, Bajor J, Szabó M, Horváth OP. Long-term results of balloon catheter dilation for benign gastric outlet stenosis. Endoscopy 2003; 35:490-495

8. Kozarek RA, Botoman VA, Patterson DJ. Long-term follow-up in patients who have undergone balloon dilation for gastric outlet obstruction. Gastrointest Endosc 1990;36:558-561.

9. Perng CL, Lin HJ, Lo WC, Lai CR, Guo WS, Lee SD. Characteristics of patients with benign gastric outlet obstruction requiring surgery after endoscopic balloon dilation. Am J Gastroenterol 1996;91:987-990.

10. Boylan JJ, Gradzka MI. Long-term results of endoscopic balloon dilatation for gastric outlet obstruction. Dig Dis Sci 1999; 44:1883-1886.

11. DiSario JA, Fennerty MB, Tietze CC, Hutson WR, Burt RW. Endoscopic balloon dilation for ulcer-induced gastric outlet obstruction. Am J Gastroenterol 1994;89:868-871.

12. Lam YH, Lau JY, Fung TM, et al. Endoscopic balloon dilation for benign gastric outlet obstruction with or without Helicobacter pylori infection. Gastrointest Endosc 2004;60:229-233.

13. Kim JH, Shin JH, Di ZH, et al. Benign duodenal strictures: treatment by means of fluoroscopically guided balloon dilation. J Vasc Interv Radiol 2005;16:543-548.

14. Coda S, Oda I, Gotoda T, Yokoi C, Kikuchi T, Ono H. Risk factors for cardiac and pyloric stenosis after endoscopic submucosal dissection, and efficacy of endoscopic balloon dilation treatment. Endoscopy 2009;41:421-426.

15. Kochhar R, Dutta U, Sethy PK, et al. Endoscopic balloon dilation in caustic-induced chronic gastric outlet obstruction. Gastrointest Endosc 2009;69:800-805.

16. Zargar SA, Kochhar R, Nagi B, Mehta S, Mehta SK. Ingestion of corrosive acids. Spectrum of injury to upper gastrointestinal tract and natural history. Gastroenterology 1989;97:702-707.

17. Zargar SA, Kochhar R, Nagi B, Mehta S, Mehta SK. Ingestion of strong corrosive alkalis: spectrum of injury to upper gastrointestinal tract and natural history. Am J Gastroenterol 1992;87:337-341.

18. Kochhar R, Malik S, Reddy YR, et al. Endoscopic balloon dilatation is an effective management strategy for caustic-induced gastric outlet obstruction: a 15-year single center experience. Endosc Int Open 2019;7:E53-E61.

19. Kochhar R, Sethy PK, Nagi B, Wig JD. Endoscopic balloon dilatation of benign gastric outlet obstruction. $J$ Gastroenterol Hepatol 2004;19:418-422.

20. Kochhar R, Malik S, Gupta P, et al. Etiological spectrum and response to endoscopic balloon dilation in patients with benign gastric outlet obstruction. Gastrointest Endosc 2018;88:899-908.

21. Banerjee S, Cash BD, Dominitz JA, et al; ASGE Standards of Practice Committee. The role of endoscopy in the management of patients with peptic ulcer disease. Gastrointest Endosc 2010;71:663-668.

22. Dormann AJ, Deppe H, Wigginghaus B. Self-expanding metallic stents for continuous dilatation of benign stenoses in gastrointestinal tract - first results of long-term follow-up in interim stent application in pyloric and colonic obstructions. Z Gastroenterol 2001;39:957-960.

23. Binkert CA, Jost R, Steiner A, Zollikofer CL. Benign and malignant stenoses of the stomach and duodenum: treatment with selfexpanding metallic endoprostheses. Radiology 1996;199:335-338.

24. Irani S, Jalai S, Ross A, Larsen M, Grimm IS, Baron TH. Use of a lumen-apposing stent to treat GI strictures. Gastrointest Endosc 2017;85:1285-1289.

25. Majumder S, Buttar NS, Gostout C, et al. Lumen-apposing covered self-expanding metal stent for management of benign gastrointestinal strictures. Endosc Int Open 2016;4:E96-E101.

26. Yang D, Nieto JM, Siddiqui A, et al. Lumen-apposing covered selfexpandable metal stents for short benign gastrointestinal strictures: a multicenter study. Endoscopy 2017;49:327-333.

27. Santos-Fernandez J, Paiji C, Shakhatreh M, et al. Lumenapposing metal stents for benign gastrointestinal tract strictures: An international multicenter experience. World J Gastrointest Endosc 2017;9:571-578.

28. Samad A, Khanzada TW, Shoukat I. Gastric outlet obstruction: change in etiology. Pakistan Journal of Surgery 2007;23:29-32.

29. Tendler DA. Malignant gastric outlet obstruction: bridging another divide. Am J Gastroenterol 2002;97:4-6.

30. Adler DG, Baron TH. Endoscopic palliation of malignant gastric outlet obstruction using self-expanding metal stents: experience in 36 patients. Am J Gastroenterol 2002;97:72-78.

31. Hussain A, Goldstein J, Shah A, et al. Ectopic pancreatic adenocarcinoma presenting as gastric outlet obstruction. Am J Gastroenterol 2000;95:2578.

32. Jeong HY, Yang HW, Seo SW, et al. Adenocarcinoma arising from an ectopic pancreas in the stomach. Endoscopy 2002;34:1014-1017.

33. Emerson L, Layfield LJ, Rohr LR, Dayton MT. Adenocarcinoma arising in association with gastric heterotopic pancreas: A case report and review of the literature. J Surg Oncol 2004;87:53-57.

34. Laasch HU, Martin DF, Maetani I. Enteral stents in the gastric outlet and duodenum. Endoscopy 2005;27:74-81.

35. Migita K, Watanabe A, Yoshioka T, Kinoshita S, Ohyama T. Clinical outcome of malignant biliary obstruction caused by metastatic gastric cancer. World J Surg 2009;33:2396-2402.

36. Kasuga A, Ishii H, Ozaka M, et al. Clinical outcome of biliary drainage for obstructive jaundice caused by colorectal and gastric cancers. Jpn J Clin Oncol 2012;42:1161-1167.

37. Papachristou D, Fortner JG. Biliary obstruction after gastrectomy for carcinoma of the stomach. Surg Gynecol Obstet 1978;147:401-404.

38. Lokich JJ, Kane RA, Harrison DA, McDermott WV. Biliary tract obstruction secondary to cancer: management guidelines and selected literature review. J Clin Oncol 1987;5:969-981.

39. Mutignani M, Tringali A, Shah SG, et al. Combined endoscopic stent insertion in malignant biliary and duodenal obstruction. Endoscopy 2007;39:440-447.

40. Dormann A, Meisner S, Verin N, Wenk Lang A. Self-expanding metal stents for gastroduodenal malignancies: systematic review of their clinical effectiveness. Endoscopy 2004;36:543-550.

41. Jeon HH, Park CH, Park JC, et al. Carcinomatosis matters: clinical outcomes and prognostic factors for clinical success of stent placement in malignant gastric outlet obstruction. Surg Endosc 2014;28:988-995.

42. Park $\mathrm{CH}$, Park JC, Kim EH, et al. Impact of carcinomatosis and ascites status on long-term outcomes of palliative treatment for patients with gastric outlet obstruction caused by unresectable gastric cancer: stent placement versus palliative gastrojejunostomy. Gastrointest Endosc 2015;81:321-332.

43. Jeurnink SM, Steyerberg EW, van Hooft JE, et al; Dutch SUSTENT Study Group. Surgical gastrojejunostomy or endoscopic stent placement for the palliation of malignant gastric outlet obstruction (SUSTENT study): a multicenter randomized trial. Gastrointest Endosc 2010;71:490-499.

44. van Hooft JE, Dijkgraaf MG, Timmer R, Siersema PD, Fockens P. Independent predictors of survival in patients with incurable malignant gastric outlet obstruction: a multicenter prospective observational study. Scand J Gastroenterol 2010;45:1217-1222.

45. Staub J, Siddiqui A, Taylor LJ, Loren D, Kowalski T, Adler DG. ERCP performed through previously placed duodenal stents: a multicenter retrospective study of outcomes and adverse events. Gastrointest Endosc 2018;87:1499-1504.

46. Woo SM, Kim DH, Lee WJ, et al. Comparison of uncovered and covered stents for the treatment of malignant duodenal obstruction caused by pancreaticobiliary cancer. Surg Endosc 2013; 27:2031-2039. 
47. van den Berg MW, Walter D, Vleggaar FP, Siersema PD, Fockens P, van Hooft JE. High proximal migration rate of a partially covered "big cup" duodenal stent in patients with malignant gastric outlet obstruction. Endoscopy 2014;46:158-161.

48. Kim CG, Choi IJ, Lee JY, et al. Covered versus uncovered selfexpandable metallic stents for palliation of malignant pyloric obstruction in gastric cancer patients: a randomized, prospective study. Gastrointest Endosc 2010;72:25-32.

49. Tierney W, Chuttani R, Croffie J, et al. Enteral stents. Gastrointest Endosc 2006;63:920-926.

50. Piesman M, Kozarek RA, Brandabur JJ, et al. Improved oral intake after palliative duodenal stenting for malignant obstruction: a prospective multicenter clinical trial. Am J Gastroenterol 2009; 104:2404-2411.

51. Kim JH, Song HY, Shin JH, et al. Metallic stent placement in the palliative treatment of malignant gastroduodenal obstructions: prospective evaluation of results and factors influencing outcome in 213 patients. Gastrointest Endosc 2007;66:256-264.

52. van Hooft JE, Uitdehaag MJ, Bruno MJ, et al. Efficacy and safety of the new WallFlex enteral stent in palliative treatment of malignant gastric outlet obstruction (DUOFLEX study): a prospective multicenter study. Gastrointest Endosc 2009;69:1059-1066.

53. Jeurnink SM, van Eijck CH, Steyerberg EW, Kuipers EJ, Siersema PD. Stent versus gastrojejunostomy for the palliation of gastric outlet obstruction: a systematic review. BMC Gastroenterol 2007;7:18.

54. Masci E, Viale E, Mangiavillano B, et al. Enteral self-expandable metal stent for malignant luminal obstruction of the upper and lower gastrointestinal tract: a prospective multicentric study. J Clin Gastroenterol 2008;42:389-394.

55. Piesman M, Kozarek RA, Brandabur JJ, et al. Improved oral intake after palliative duodenal stenting for malignant obstruction: a prospective multicenter clinical trial. Am J Gastroenterol 2009; 104:2404-2411.

56. Tringali A, Didden P, Repici A, et al. Endoscopic treatment of malignant gastric and duodenal strictures: a prospective, multicenter study. Gastrointest Endosc 2014;79:66-75.

57. Yang Z, Wu Q, Wang F, Ye X, Qi X, Fan D. A systematic review and meta-analysis of randomized trials and prospective studies comparing covered and bare self-expandable metal stents for the treatment of malignant obstruction in the digestive tract. Int J Med Sci 2013;10:825-835.

58. Hamada T, Hakuta R, Takahara N, et al. Covered versus uncovered metal stents for malignant gastric outlet obstruction: Systematic review and meta-analysis. Dig Endosc 2017;29:259-271.

59. Pan YM, Pan J, Guo LK, Qiu M, Zhang JJ. Covered versus uncovered self-expandable metallic stents for palliation of malignant gastric outlet obstruction: a systematic review and meta-analysis. $B M C$ Gastroenterol 2014;14:170.

60. Didden P, Spaander MC, de Ridder R, et al. Efficacy and safety of a partially covered stent in malignant gastric outlet obstruction: a prospective Western series. Gastrointest Endosc 2013;77:664-668.

61. Oh D, Lee SS, Song TJ, et al. Efficacy and safety of a partially covered duodenal stent for malignant gastroduodenal obstruction: a pilot study. Gastrointest Endosc 2015;82:32-36.

62. Song HY, Shin JH, Yoon CJ, et al. A dual expandable nitinol stent: experience in 102 patients with malignant gastroduodenal strictures. J Vasc Interv Radiol 2004;15:1443-1449.

63. Jang JK, Song HY, Kim JH, Song M, Park JH, Kim EY. Tumor overgrowth after expandable metallic stent placement: experience in 583 patients with malignant gastroduodenal obstruction. AJR Am J Roentgenol 2011;196:W831-W836.

64. Moon JH, Choi HJ, Ko BM, et al. Combined endoscopic stent-instent placement for malignant biliary and duodenal obstruction by using a new duodenal metal stent (with videos). Gastrointest Endosc 2009;70:772-777.
65. Sasaki T, Isayama $\mathrm{H}$, Nakai $\mathrm{Y}$, et al. Clinical outcomes of secondary gastroduodenal self-expandable metallic stent placement by stentin-stent technique for malignant gastric outlet obstruction. Dig Endosc 2015;27:37-43.

66. Kim CG, Choi IJ, Lee JY, et al. Outcomes of second self-expandable metallic stent insertion for malignant gastric outlet obstruction. Surg Endosc 2014;28:281-288.

67. Ly J, O'Grady G, Mittal A, Plank L, Windsor JA. A systematic review of methods to palliate malignant gastric outlet obstruction. Surg Endosc 2010;24:290-297.

68. Jeurnink SM, Steyerberg EW, Hof G, van Eijck CH, Kuipers EJ, Siersema PD. Gastrojejunostomy versus stent placement in patients with malignant gastric outlet obstruction: a comparison in 95 patients. J Surg Oncol 2007;96:389-396.

69. Mehta S, Hindmarsh A, Cheong E, et al. Prospective randomized trial of laparoscopic gastrojejunostomy versus duodenal stenting for malignant gastric outflow obstruction. Surg Endosc 2006;20:239-242.

70. Fiori E, Lamazza A, Volpino P, et al. Palliative management of malignant antro-pyloric strictures. Gastroenterostomy vs. endoscopic stenting. A randomized prospective trial. Anticancer Res 2004;24:269-271.

71. Jang S, Stevens T, Lopez R, Bhatt A, Vargo JJ. Superiority of gastrojejunostomy over endoscopic stenting for palliation of malignant gastric outlet obstruction. Clin Gastroenterol Hepatol 2018 Oct 31 [Epub ahead of print]. doi: 10.1016/j.cgh.2018.10.042

72. Mortenson MM, Ho HS, Bold RJ. An analysis of cost and clinical outcome in palliation for advanced pancreatic cancer. Am J Surg 2005; 190:406-411.

73. Johnsson E, Thune A, Liedman B. Palliation of malignant gastroduodenal obstruction with open surgical bypass or endoscopic stenting: clinical outcome and health economic evaluation. World J Surg 2004;28:812-817.

74. Yim HB, Jacobson BC, Saltzman JR, et al. Clinical outcome of the use of enteral stents for palliation of patients with malignant upper GI obstruction. Gastrointest Endosc 2001;53:329-332.

75. Siddiqui A, Spechler SJ, Huerta S. Surgical bypass versus endoscopic stenting for malignant gastroduodenal obstruction: a decision analysis. Dig Dis Sci 2007;52:276-281.

76. Zucchi E, Fornasarig M, Martella L, et al. Decompressive percutaneous endoscopic gastrostomy in advanced cancer patients with small-bowel obstruction is feasible and effective: a large prospective study. Support Care Cancer 2016;24:2877-2882.

77. Perez-Miranda M, Tyberg A, Poletto D, et al. EUS-guided gastrojejunostomy versus laparoscopic gastrojejunostomy: an international collaborative study. J Clin Gastroenterol 2017; 51:896-899.

78. Khashab MA, Bukhari $\mathrm{M}$, Baron $\mathrm{TH}$, et al. International multicenter comparative trial of endoscopic ultrasonographyguided gastroenterostomy versus surgical gastrojejunostomy for the treatment of malignant gastric outlet obstruction. Endosc Int Open 2017;5:E275-E281.

79. Itoi $\mathrm{T}$, Itokawa $\mathrm{F}$, Uraoka $\mathrm{T}$, et al. Novel EUS-guided gastrojejunostomy technique using a new double-balloon enteric tube and lumen-apposing metal stent (with videos). Gastrointest Endosc 2013;78:934-939.

80. Itoi $\mathrm{T}$, Baron $\mathrm{TH}, \mathrm{Khashab} \mathrm{MA}$, et al. Technical review of endoscopic ultrasonography-guided gastroenterostomy in 2017. Dig Endosc 2017;29:495-502.

81. Tyberg A, Perez-Miranda M, Sanchez-Ocaña R, et al. Endoscopic ultrasound-guided gastrojejunostomy with a lumen-apposing metal stent: a multicenter, international experience. Endosc Int Open 2016;4:E276-E281.

82. Khashab MA, Kumbhari V, Grimm IS, et al. EUS-guided gastroenterostomy: the first U.S. clinical experience (with video). Gastrointest Endosc 2015;82:932-938. 